\title{
Co-Mn oxides supported on hierarchical macro-mesoporous silica for CO and VOCs oxidation
}

\author{
S. Todorova ${ }^{\mathrm{a}, *}$, J.L. Blin ${ }^{\mathrm{b}}$, A. Naydenov ${ }^{\mathrm{c}}$, B. Lebeau ${ }^{\mathrm{d}, \mathrm{e}}$, D. Karashanova ${ }^{\mathrm{f}}, \mathrm{H}$. Kolev ${ }^{\mathrm{a}}$, P. Gaudin ${ }^{\mathrm{b}}$,

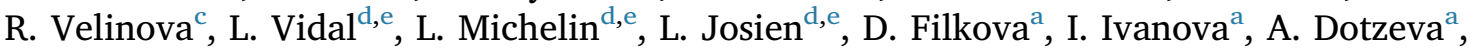 \\ K. Tenchev ${ }^{\mathrm{a}}$ \\ ${ }^{a}$ Institute of Catalysis, Bulgarian Academy of Sciences, Acad. G. Bonchev St., Bldg. 11, 1113 Sofia, Bulgaria \\ ${ }^{\mathrm{b}}$ Université de Lorraine/CNRS, L2CM, UMR7053, F-54506 Vandoeuvre-lès-Nancy Cedex, France \\ ${ }^{\mathrm{c}}$ Institute of General and Inorganic Chemistry, Bulgarian Academy of Sciences, Acad. G. Bonchev St., Bldg. 11, 1113 Sofia, Bulgaria \\ ${ }^{\mathrm{d}}$ Université de Haute Alsace (UHA), CNRS, IS2M, UMR 7361, F-68100 Mulhouse, France \\ ${ }^{\mathrm{e}}$ Université de Strasbourg, F-67000 Strasbourg, France \\ ${ }^{\mathrm{f}}$ Institute of Optical Materials and Technologies "Acad. Jordan Malinowski", Bulgarian Academy of Sciences, Acad. G. Bonchev St., Bldg. 109, 1113 Sofia, Bulgaria
}

\section{A R T I C L E I N F O}

\section{Keywords:}

Hierarchical macro-mesoporous silica

Co-Mn mixed oxides

$n$-Hexane combustion

CO oxidation

\begin{abstract}
A B S T R A C T
The hierarchical macro-mesoporous silica (MMS) was used for a first time as a support for catalysts for oxidation reactions. The macro-mesoporous silica was synthesized by the emulsions templating mechanism and modified separately or simultaneously using cobalt and manganese oxides. The obtained materials were characterized by different physicochemical methods and tested in the oxidation of $\mathrm{CO}$ and $n$-hexane combustion reactions. The modification of the MMS materials does not change significantly the mesopores characteristics; however, its pores are partially blocked by the oxides. For Co-MM sample agglomerates consisting of $\mathrm{Co}_{3} \mathrm{O}_{4}$ with average size of $100-150 \mathrm{~nm}$ and small spherical aggregates, encapsulated in the mesopores are formed. The amorphous manganese oxide preferentially fills up the mesopores in Mn-MM sample. Mixed oxide Co-Mn phases situated in the mesoporous network are formed in the bi-component Co-Mn samples. No significant change is observed either in the texture, or in the structural features of the catalysts after reaction.

The highest catalytic activity for Co-MM sample in CO and $n$-hexane oxidation is related to the predomination of $\mathrm{Co}^{3+}$ species on the surface of $\mathrm{Co}_{3} \mathrm{O}_{4}$ and the more accessible oxide particles located outside the mesopores. The encapsulation of mixed Co-Mn oxides particles in the pores of the macro-mesoporous silica is responsible for a lower catalytic activity in comparison with that of the mono-component cobalt sample.
\end{abstract}

\section{Introduction}

Air pollution has become one of European Union's main environmental policy concerns since the late 1970s (http://ec.europa.eu/ environment/index_en.htm). In 2013, the EU proposed a Clean Air Policy Package to further reduce emissions of air pollutants until 2030. The main air pollutants are $\mathrm{PM}, \mathrm{SO}_{2}, \mathrm{NH}_{3}, \mathrm{NOx}$, volatile organic compounds (VOCs), $\mathrm{CH}_{4}$. Abatement of volatile organic compounds (VOCs) and carbon monoxide (CO) in the waste gases is an important task in the field of environmental protection and odour control.

There are many different techniques for VOCs removal, such as adsorption, absorption, bio-filtering, thermal and catalytic combustion [1-3]. The advantages of the catalytic incineration are that it takes place at temperatures much lower than those required for thermal incineration, resulting in lower costs and low NOx formation. There is a great number of successful commercial catalysts, developed for $\mathrm{CO}$ and VOC oxidation. Nevertheless, there still exists a demand for development of new optimized catalysts with increased efficiency of mass and heat transfer [4,5] and which do not contain any noble metals.

In our previous works a considerable increase in activity was established for bi-component Co-Mn samples, when comparing with mono component cobalt or manganese [6-10]. The deactivation of the bi-component Co-Mn samples was observed after stability test as a result of sintering of the oxide phase. The investigation was extended further by synthesizing of Co-Mn catalysts supported on SBA-15 [9] and the observed resistance towards agglomeration was attributed to the mesoporous structure.

Hierarchically porous catalysts are of recent scientific and

\footnotetext{
* Corresponding author.

E-mail address: todorova@ic.bas.bg (S. Todorova).
} 
technological interest due to their improved diffusion performances and high specific surface areas. The hierarchically porous silica has more positive effect comparing with common silica supports. On the one hand, porous silica materials not only possess all the virtues of inorganic materials but they also have a large specific surface areas, welldefined tuneable pore sizes and adjustable hydrophobic or hydrophilic character [11,12], which will provide great opportunities for good immobilization, large loading and high dispersion of catalytic species. On the other hand, the advantage of the hierarchically porous materials is that the large macro-pores combined with the mesoporous structure attribute to the materials large transport channels accompanied by a highly active surface area [13], which is beneficial for the catalytic activity of the materials.

We expect that the combination of transition metal oxides $\left(\mathrm{Co}_{3} \mathrm{O}_{4}\right.$ and $\mathrm{MnOn}$ ) and hierarchical macro-mesoporous material should produce highly active catalysts due to the improved diffusion of the reagents inside the pore system on the one hand, and to the prevention of agglomeration of the oxide particles. This work is a continuation of our previous research and it is aimed at establishing the influence of the carrier structure on the activity of mixed cobalt-manganese catalysts in the reaction of complete oxidation of $n$-hexane and CO. Hierarchical macro-mesoporous silicas will be used for the first time as support of mixed oxide catalysts. The structural and catalytic properties of series of mono-component cobalt and manganese and bi-component Co-Mn catalysts will be studied.

\section{Materials and methods}

\subsection{Catalysis preparation}

For synthesis of macro-mesoporous materials fluorinated surfactants are used. They were provided by DuPont Co., and they have an average chemical composition of $\mathrm{C}_{8} \mathrm{~F}_{17} \mathrm{C}_{2} \mathrm{H}_{4}\left(\mathrm{OC}_{2} \mathrm{H}_{4}\right)_{9} \mathrm{OH}$ and $\mathrm{C}_{7} \mathrm{~F}_{15} \mathrm{C}_{2} \mathrm{H}_{4}\left(\mathrm{OC}_{2} \mathrm{H}_{4}\right)_{8} \mathrm{OH}$. They are respectively labeled as $\mathrm{R}_{8}^{\mathrm{F}}(\mathrm{EO})_{9}$ and $\mathrm{R}_{7}^{\mathrm{F}}(\mathrm{EO})_{8}$. In both cases the hydrophilic chain moiety exhibited a Gaussian chain length distribution and the hydrophobic part is composed of well-defined mixture of fluorinated tails. Perfluorodecalin $\left(\mathrm{C}_{10} \mathrm{~F}_{18}\right)$, which is a molecule with two saturated rings, was purchased from Aldrich.

Macro-mesoporous supports (MMS) were synthesized according to a procedure previously reported [14] through the emulsions templating mechanism. However, due to a batch change of $\mathrm{R}_{7}^{\mathrm{F}}(\mathrm{EO})_{8}$ surfactant, in this work, the emulsion was formulated from a mixture containing 30 wt. $\% \mathrm{R}_{8}^{\mathrm{F}} \mathrm{EO}_{9}$ and 70 wt. $\%$ of $\mathrm{R}_{7}^{\mathrm{F}} \mathrm{EO}_{8}$. Before the incorporation of oil, a micellar solution containing $25 \mathrm{wt} . \%$ of the surfactant mixture in water at $\mathrm{pH}=0.3$ was prepared. The concentration of $\mathrm{C}_{10} \mathrm{~F}_{18}$, added to the micellar solution was $20 \mathrm{wt} . \%$. Tetramethoxysilane (TMOS), used as the silica source, was added dropwise. The surfactant/silica molar ratio was fixed at 0.5. The obtained gel was sealed in Teflon autoclaves and heated during $24 \mathrm{~h}$ at $100{ }^{\circ} \mathrm{C}$. The final product was recovered after ethanol extraction with a soxhlet apparatus in the course of $48 \mathrm{~h}$.

For the preparation of both types of single component samples (Co or Mn) as well as bi-component samples the "two-solvent" technique was used. The procedure was described in [9]. After preparation the solid phase was recovered by filtration and dried up in air and then calcined for $3 \mathrm{~h}$ at $500{ }^{\circ} \mathrm{C}$ in air. The as prepared samples were denoted as Co-MM, Mn-MM, 1Co05Mn-MM, 1Co1Mn -MM, and 1Co2Mn- MM, where the number represents the Mn and Co number of moles.

\subsection{Catalysts characterization}

The obtained materials were characterized by SAXS, $\mathrm{N}_{2}$ adsorptiondesorption, X-ray diffraction, SEM and TEM microscopy.

Small angle X-ray scattering (SAXS) data were collected on a "SAXSess $\mathrm{mc}^{2}$ " instrument (Anton Paar), using line-collimation system. This instrument is attached to an ID 3003 laboratory X-Ray generator
(General Electric) equipped with a sealed X-Ray tube (PANalytical, $\lambda$ $\mathrm{Cu}, \mathrm{K} \alpha=0.1542 \mathrm{~nm}$ ) operating at $40 \mathrm{kV}$ and $50 \mathrm{~mA}$ [9].

Nitrogen adsorption-desorption isotherms were carried out at $-196{ }^{\circ} \mathrm{C}$ over a wide relative pressure (P/P0) range from 0.010 to 0.995 with a volumetric adsorption analyzer TRISTAR 3000 manufactured by Micromeritics. Before measurements, the samples were degassed under vacuum (pressure $=0.13 \mathrm{mBar}$ ) at $25^{\circ} \mathrm{C}$ for $16 \mathrm{~h}$. The specific surface area of each sample was calculated by the Brunauer-Emmett-Teller (BET) method [15]. The pore diameter and the pore size distribution were determined from the adsorption branch of the corresponding isotherm using the Barret-Joyner-Halenda (BJH) method [16].

Wide angles X-ray diffraction patterns were recorded on a PANalytical MPD X'Pert Pro diffractometer operating with $\mathrm{Cu} \mathrm{K}_{\alpha}$ radiation $\left(\mathrm{K}_{\alpha}=0.15418 \mathrm{~nm}\right)$ equipped with an $\mathrm{X}^{\prime}$ Celerator real-time multiple strip detector (active length $=2.12^{\circ} 2 \theta$ ).

Scanning Electron Microscopy (SEM) was performed using a JEOL JSM-7900F microscope. The high resolution images were obtained at low accelerating voltages $0.5-1 \mathrm{kV}$. Elemental X-ray maps were collected using a BRUKER QUANTAX energy dispersive spectrometer (EDS). In order to minimize the excitation volume and increase the spatial resolution of these maps, a low electron beam energy $(5 \mathrm{kV})$ was applied.

Transmission Electron Microscopy (TEM) images and chemical analyses of the samples were performed using a JEOL ARM200-CFEG microscope operating at $200 \mathrm{kV}$ The EDX analyses and mappings were performed using a JEOL Centurio detector.

HRTEM JEOL JEM2100 was used to perform the TEM, High Resolution Transmission Electron Microscopy (HRTEM) and Selected Area Electron Diffraction (SAED) analysis of the samples. The accelerating voltage during the experiments was kept at $200 \mathrm{kV}$. TEM and HRTEM images were acquired at magnifications of $40,000 \times$ and $600,000 \times$, respectively, SAED patterns - at $250 \mathrm{~mm}$ camera length. A preliminary preparation of the powdered samples was applied, consisting in ethanol suspension preparation for each sample and drying a drop of each suspension on a standard TEM Cu grid, covered by amorphous carbon layer.

Intrusion/extrusion mercury porosimetry was applied using a Micromeritics Autopore IV 9500 porosimeter.

X-ray photoelectron spectroscopy (XPS) was carried out using ESCALAB MkII (VG Scientific) and the processing of the measured spectra has been described in [6,7].

Temperature-programmed reduction (TPR) and temperature-programmed oxidation experiments are described in [9].

\subsection{Catalytic activity}

The catalytic properties were tested in the complete oxidation reactions of $n$-hexane and carbon monoxide.

The catalytic activity tests in $\mathrm{CO}$ oxidation reaction were carried out in a continuous flow type of glass reactor described in [9] at atmospheric pressure with a catalyst bed loading of about $0.5 \mathrm{~cm}^{3}$ (fraction $0.25-0.31 \mathrm{~mm}$ ). The feed gaseous mixture at the inlet consisted of $1 \mathrm{vol}$. $\%$ CO, 10 vol. $\% \mathrm{O}_{2}$ and $\mathrm{He}$ for balance to 100 vol.\% and $\mathrm{GHSV}_{\text {STP }}=60,000 \mathrm{~h}^{-1}$.

Catalytic activity tests in the complete oxidation reaction of $n$ hexane were performed using an integrated quartz micro-reactor and mass spectrometer analysis system (CATLAB, Hiden Analytical, UK). The $n$-hexane inlet concentration in synthetic air was kept at $1000 \mathrm{ppm}$. The same GHSV $\mathrm{STP}_{\text {as }}$ that for CO tests was used $\left(60,000 \mathrm{~h}^{-1}\right)$.

\section{Results and discussion}

The characterization of all catalyst samples was done both for the as prepared samples and after their $n$-hexane oxidation reaction. 

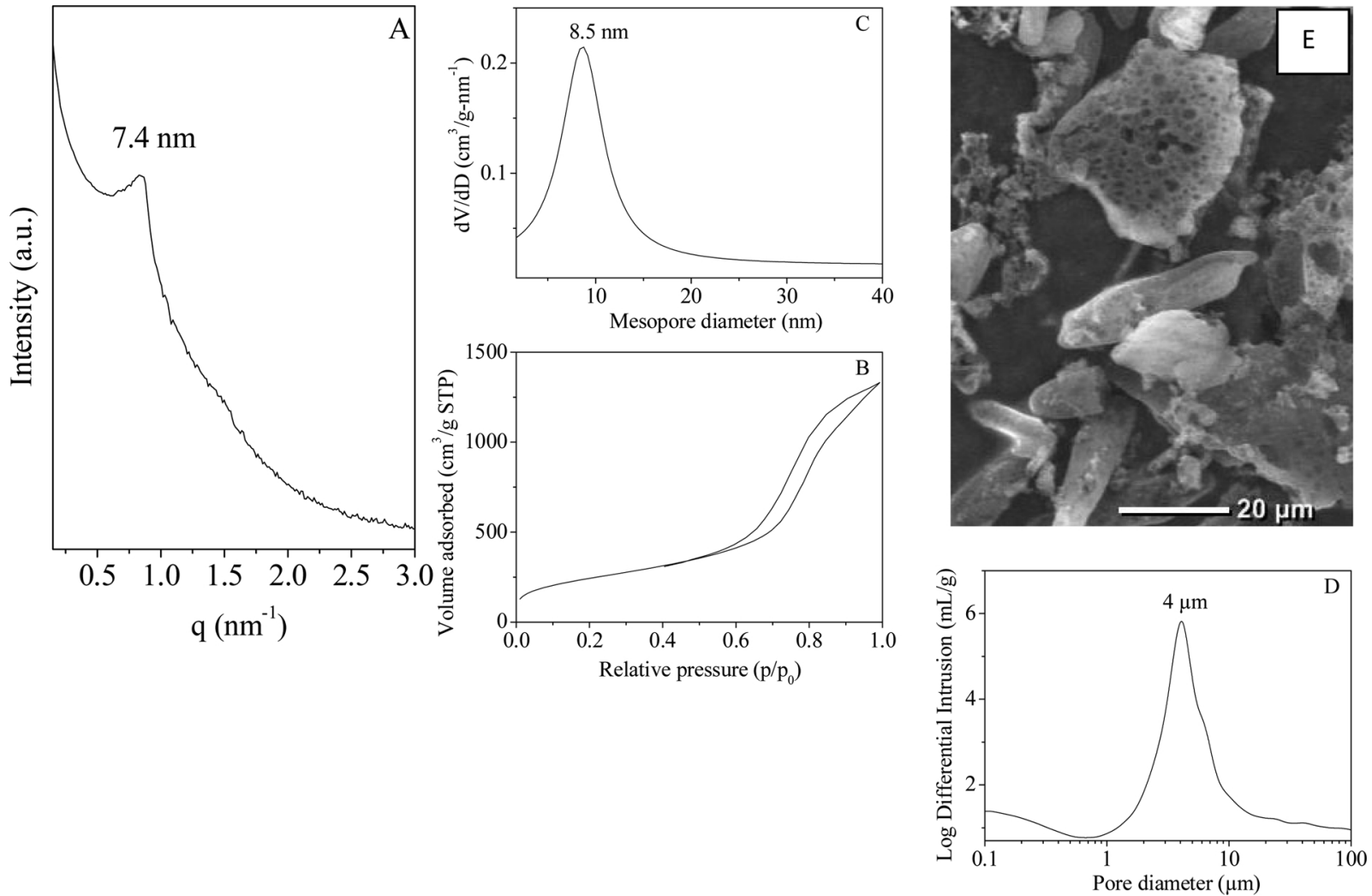

Fig. 1. SAXS pattern (A), nitrogen adsorption-desorption isotherm (B), mesopore size distribution (C), macropore size distribution (D) and SEM image of the bare macro-mesoporous silica (E).

\subsection{Characterization of catalyst samples}

\subsubsection{Structural and textural characterization of the macro-mesoporous} material and CoMn supported macro-mesoporous silica catalysts

The SAXS pattern of bare material (Fig. 1A) exhibits a reflection at $7.4 \mathrm{~nm}$, characteristic of a wormhole-like mesostructure, as observed in case of MMS. This peak gives an indication of the average pore-to-pore distance in the disordered wormhole framework, which presents a lack of long-range crystallographic order. The presence of the mesoporosity is evidenced by $\mathrm{N}_{2}$ sorption analyses corresponding to type IV isotherm (Fig. 1B), characteristic of mesoporous materials according to the IUPAC classification [17], is evidenced. However, at high relative pressures $(\mathrm{p} / \mathrm{p} 0>0.9)$ the adsorbed volume of $\mathrm{N}_{2}$ increases significantly instead of remaining constant due to saturation, indicating the presence of a secondary porosity. The specific surface area and pore volume values are respectively $880 \mathrm{~m}^{2} / \mathrm{g}$ and $1.63 \mathrm{~cm}^{3} / \mathrm{g}$. The mesopore diameter distribution determined by using the BJH method is centered at about $8.5 \mathrm{~nm}$ (Fig. 1C). The macropores size distribution has been determined by mercury porosity. One rather broad component centered on $4 \mu \mathrm{m}$ is detected (Fig. 1D). It can be attributed to the fingerprint of the oil droplet dispersed in the outer aqueous phase. The values of the skeleton density and of the porosity are $1.6 \mathrm{~g} / \mathrm{cm}^{3}$ and $91.5 \%$, respectively. The presence of the macropores is further confirmed by SEM (Fig. 1E) while the mesopores were visualized by TEM (Figs. 3 and 4).

After the introduction and decomposition of the cobalt and/or manganese precursors the large peak observed in the SAXS pattern becomes less resolved and its intensity decreases (Fig. 1 from Supplementary). This could be explained by the partial filling up of the macro-mesoporous materials with the metal oxide particles as is reported by Wang et al. for pure mesoporous materials [18]. This could also indicate that a partial collapse of the mesopore occurs during the impregnation process.

Whatever the impregnated material is, a type IV isotherm with a H2 hysteresis loop (Fig. 2 from Supplementary), characteristic of MMS materials is obtained. The mesoporosity is therefore maintained after the impregnation process. Comparing with the bare silica material, a decrease in the adsorbed volume of the $\mathrm{dV} / \mathrm{dD}$ value in the pore size distribution (Fig. 3A from Supplementary), decrease in the specific surface and in the pore volume (Fig. 3Ab from Supplementary) is noted. For example, the specific surface area and the mesopore volume varies from 880 to 493,448 and $438 \mathrm{~m}^{2} / \mathrm{g}$ and from 1.63 to $0.72,0.63$ and $0.62 \mathrm{~cm}^{3} / \mathrm{g}$ when Co, Mn and both Co and Mn with a 1:1 ratio are incorporated inside the macro-mesoporous material, respectively. Meantime, the maximum of the mesopore size distribution is shifted towards lower value, between 4.8 and $5.6 \mathrm{~nm}$, depending on the ratio between Co and Mn. All of these variations are in accordance with the introduction of the metals species in the mesopores and their shrinkage as a result of calcination at $500{ }^{\circ} \mathrm{C}$.

The wide-angle $\mathrm{X}$-ray diffraction patterns of the Co sample show low intensive and broad peaks corresponding to $\mathrm{Co}_{3} \mathrm{O}_{4}$ nanocrystals (Fig. 2). No X-ray diffraction peak was observed for the Mn sample. Broad line at a slightly lower value of $2 \theta(2 \theta=36,5)$ in comparison with that for single component cobalt sample is visible in the XRD spectra of bicomponent Co-Mn catalyst. The shift in the $2 \theta$ position increases with the Co-Mn molar ratio decrease from 1:0.5 to 1:2. As it was previously reported for the CoMn/SBA-15 materials [9], this shift indicates the formation of $\mathrm{Mn}_{\mathrm{x}} \mathrm{Co}_{3-\mathrm{x}} \mathrm{O}_{4}$ mixed oxides [19]. It is already known that Co and Mn can form stable mixed oxides [19] because both Co and Mn cations have similar ionic radii. The formation of mixed oxides was confirmed by HRTEM and SAED analyses. SAED pattern of $1 \mathrm{Co} 0.5 \mathrm{Mn}$ sample shows the presence of the following phases: $\mathrm{MnCo}_{2} \mathrm{O}_{4}$ cubic, ( $\mathrm{a}=8.290$, PDF 84-0482), $\mathrm{Co}_{3} \mathrm{O}_{4}$ cubic ( $\mathrm{a}=8.085$, PDF 78-1969), $\mathrm{MnO}_{2}$ hexagonal $\left(\mathrm{a}=2.766, \mathrm{c}=4.412\right.$, PDF 89-5171); $\mathrm{Mn}_{3} \mathrm{O}_{4}$ tetragonal $(\mathrm{a}=5.763, \mathrm{c}=9.456$, PDF 89-4837) (Fig. 3). The next phases are distinguished for the sample $1 \mathrm{Co} 0.5 \mathrm{Mn}: \mathrm{Co}_{3} \mathrm{O}_{4}$ cubic $(\mathrm{a}=8.085$, PDF 78-1969), $\mathrm{MnCo}_{2} \mathrm{O}_{4}$ cubic $\left(\mathrm{a}=8.290\right.$, PDF 84-0482) and $\mathrm{CoMnO}_{3}$ 


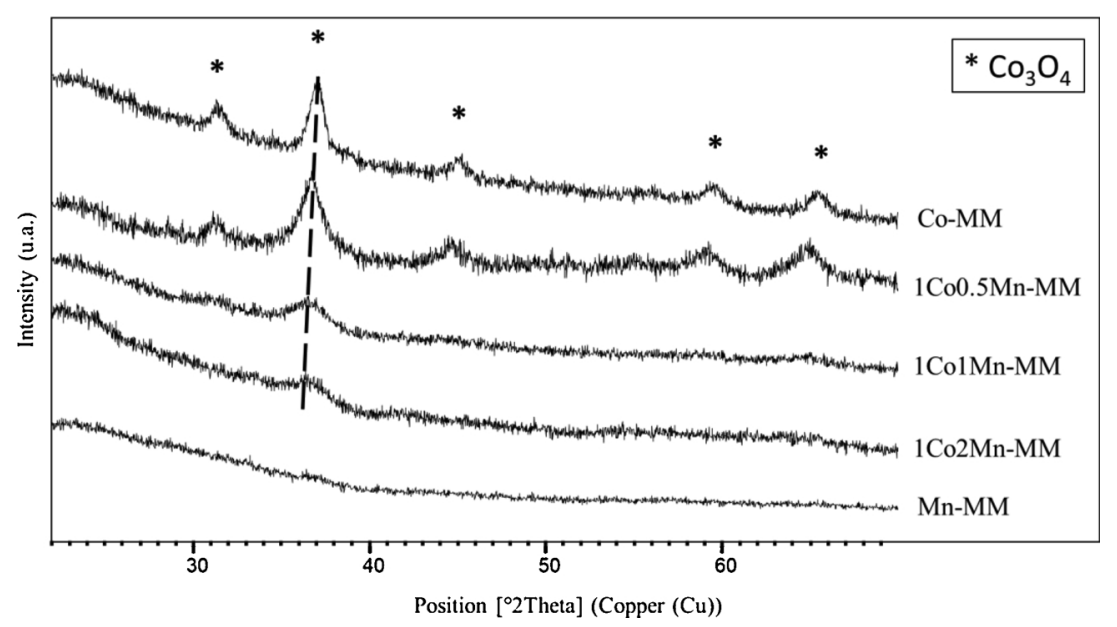

Fig. 2. Wide angles XRD patterns of Co, Mn and mixed oxide samples before reaction.

rhombohedral ( $\mathrm{a}=5.385, \alpha=54.52$, PDF 75-2090) (Fig. 4).

The high-magnification SEM image of Co-MM, Mn-MM and 1Co1Mn-MM samples displayed in Fig. 4 from the supplement shows mesopores regular in size consistent with wormlike mesopores detected by SAXS. At low magnification SEM image of 1Co1Mn-MM sample shows large particles with macropores corresponding to the macromesoroporous silica that are covered by smaller particles (Fig. 4 from Supplementary material). EDX elemental mappings recorded at low magnification show that $\mathrm{Co}$ and $\mathrm{Mn}$ are present everywhere in/on silica particles (Fig. 5 from Suplement). The dispersion degree of Co and Mn is not homogeneous and it appears mainly as aggregates corresponding to the small particles observed in the related SEM image. The Co and $\mathrm{Mn}$ mappings are also consistent with the co-presence of the two elements.
TEM images of Co, Mn and bi-component CoMn sample show large dark agglomerates that are in contrast with the dark grey silica walls and the light grey voids of the wormlike mesopores (Fig. 5). For Co sample the agglomerates have an average size of $100-150 \mathrm{~nm}$ and look more or less interpenetrated in the mesopores of the silica network (Fig. 5A1). High magnification images reveal an aggregation of small spherical particles about $5 \mathrm{~nm}$ in diameter, fitting with the mesopore size (Fig. 5A2). Agglomerates observed for Mn sample look more spread out and in average smaller in size than those observe for Co-MM (Fig. 5B1). The small particles that constitute them appear to be more interpenetrated inside the mesopores (Fig. 5B2). In the bi-component Co-Mn sample dark aggregates as large as the ones observed for Co are present (Fig. 5C1, C2). Co and Mn element mapping from EDX analyses confirmed the only presence of Co, Mn, and bi-component Co-Mn
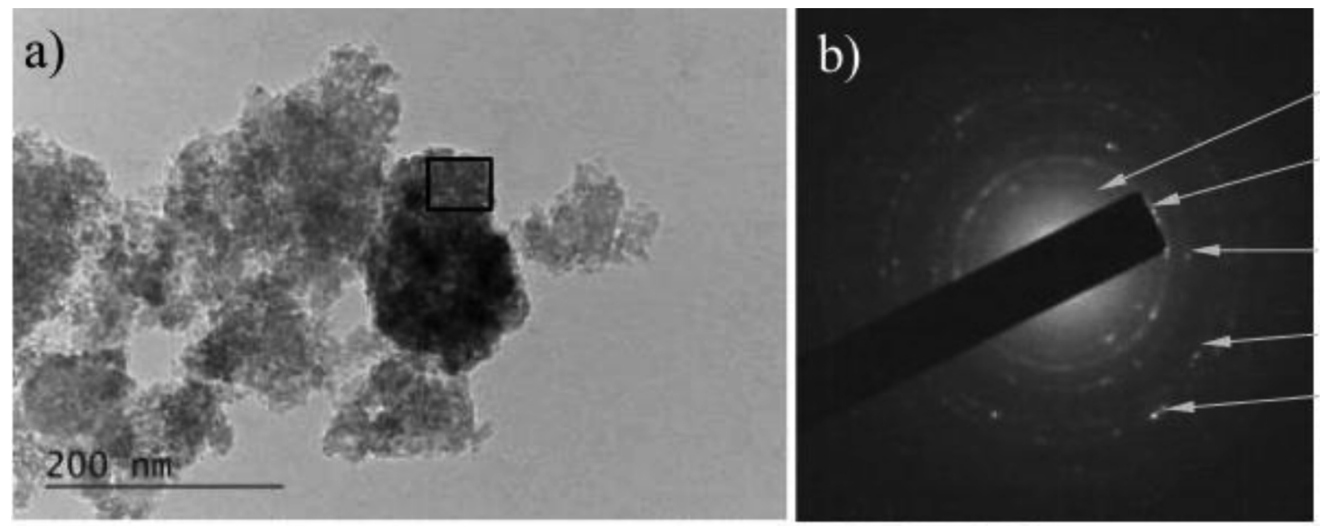

$220 \mathrm{Co}_{3} \mathrm{O}_{4}$ cubic

$311 \mathrm{Co}_{3} \mathrm{O}_{4}$ cubic, $202 \mathrm{CoMn}_{2} \mathrm{O}_{4}$ tetr

$400 \mathrm{Co}_{3} \mathrm{O}_{4}$ cubic, $220 \mathrm{MnO}_{2}$ ortho $224 \mathrm{Mn}_{3} \mathrm{O}_{4}$ tetra $002 \mathrm{MnO}_{2}$ ortho, $440 \mathrm{Co}_{3} \mathrm{O}_{4}$ cubic
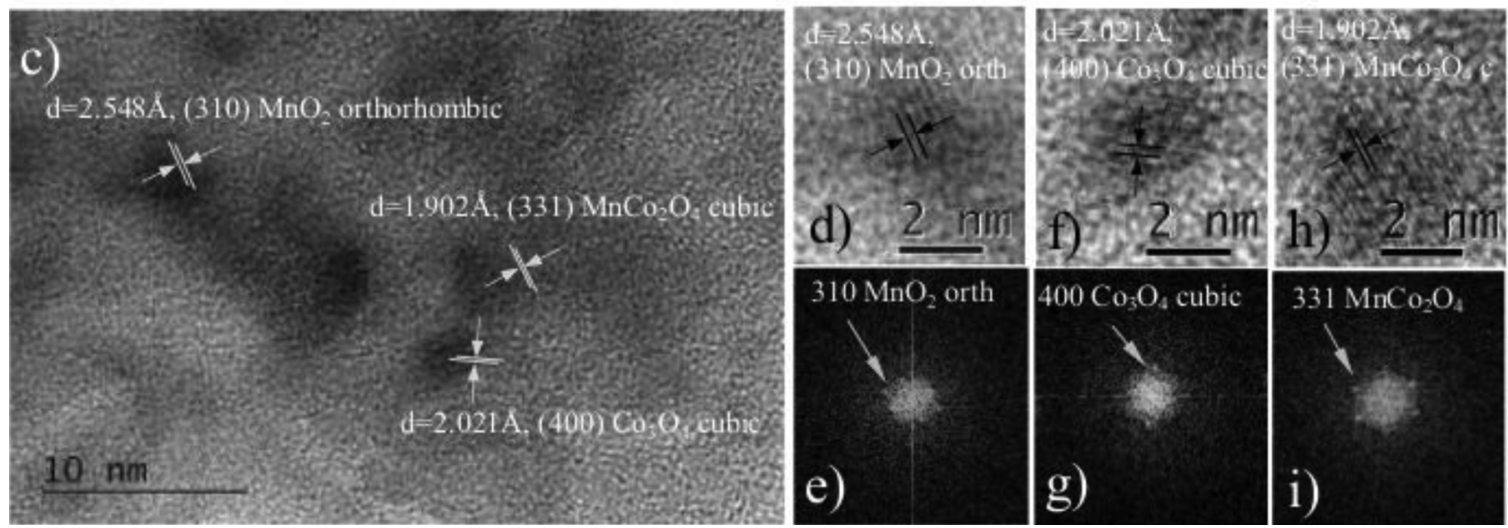

Fig. 3. TEM image of 1Co1Mn-MM sample (a), the corresponding SAED patterns with phase identification (b), HRTEM image of the marked in a) area (c), HRTEM images of individual particles in the sample (d) and f)) and their FFT patterns, representing the corresponding phases (e) and g)). 

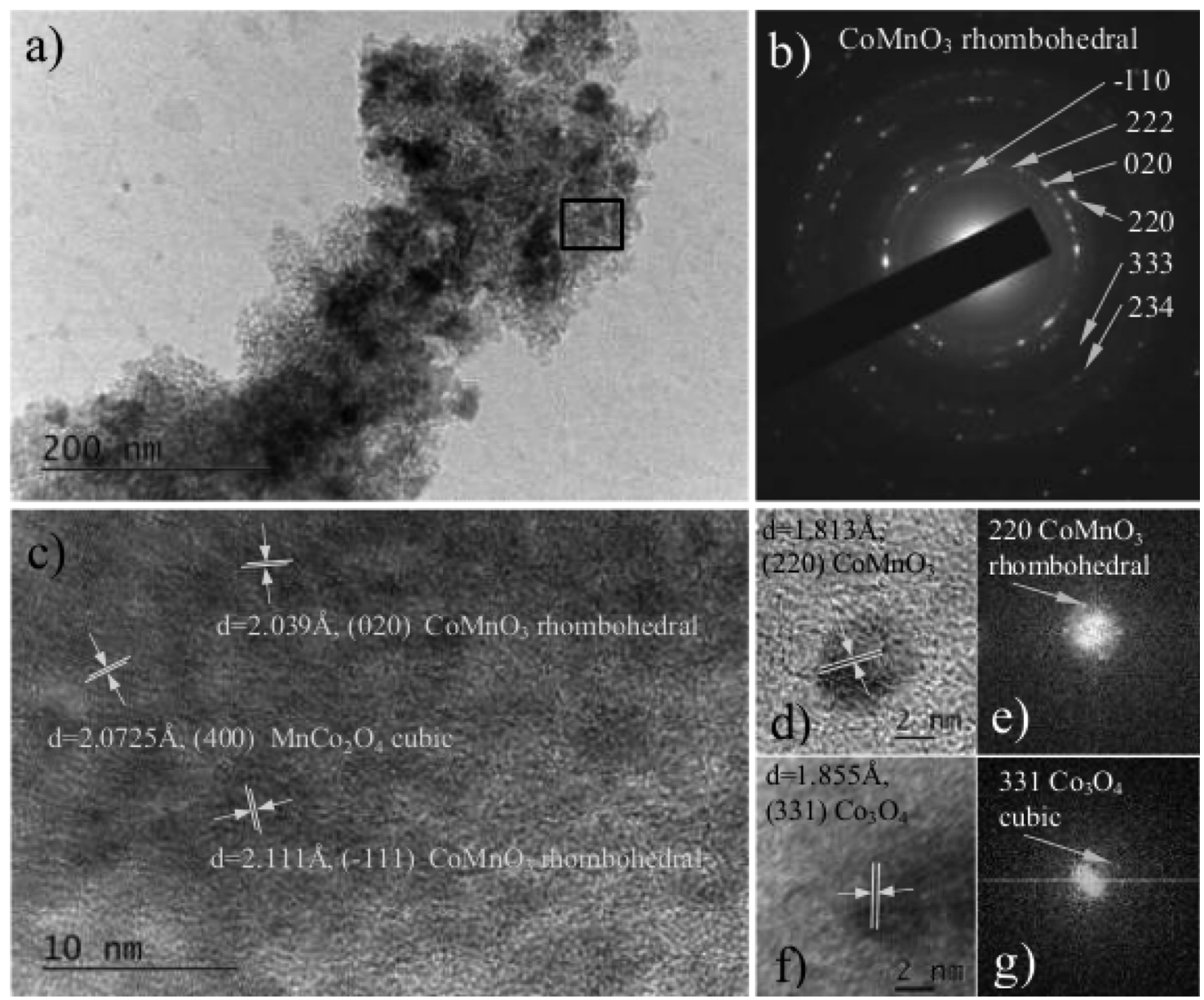

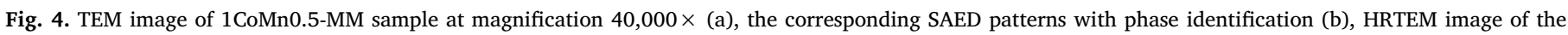

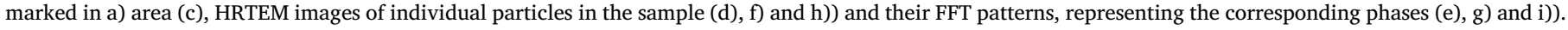

nanoparticles for Co-MM, Mn-MM and 1Co1Mn-MM samples, respectively (Fig. 6 Supplementary). The presence of Co and Mn in the same phase for bi-component CoMn samples confirm the formation of mixed oxides as revealed by wide angles XRD and HRTEM analysis.

After reaction except for a slight decrease in the adsorbed volume (Fig. 2B from Supplement), and of the $\mathrm{dV} / \mathrm{dD}$ values (Fig. 3B of the Supplement), no significant change is noted neither in the textural nor in the structural features of the catalysts. The mesoporosity is not affected by the conditions, under which the catalytic oxidation of $\mathrm{CO}$ and $n$-hexane oxidation is performed. TEM observations (Fig. 7 from Supplement) confirm that no significant structural changes occurred during the reaction. Nevertheless, wide angles XRD analyses showed the apparition of three low intensity and broad XRD peaks in Mn-MM sample that could correspond to $\mathrm{MnO}_{2}$ pyrolusite (card n $01-071-4824$ ) and $\mathrm{Mn}_{2} \mathrm{O}_{3}$ bixbyite (card $\mathrm{n}^{\circ} 00-041-1442$ ) nanocrystallites (Fig. 8 from Supplementary). Formation of $\mathrm{Mn}_{2} \mathrm{CoO}_{4}$ (card $\mathrm{n}^{\circ} 04-008-978$ ) and $\mathrm{Mn}_{2} \mathrm{O}_{3}$ bixbyite (card $\mathrm{n}^{\circ} 00-041-1442$ ) is visible in the XRD patterns of $1 \mathrm{Co} 2 \mathrm{Mn}-\mathrm{MM}$. These structural changes are probably the result of some sintering of oxide particles during the reaction.

\subsubsection{Characterization of the supported metal oxide species}

The oxidation states of Co and Mn on the surface is examined by XPS. Fig. 9 from Supplementary data shows an example of curve fitting of Co2 $\mathrm{p}_{1 / 2}$ (on the left-hand side) and Mn2p (right-hand side) core levels of investigated samples before the catalytic activity test. The peaks at binding energies (BEs) at $795.0 \mathrm{eV}$ and $796.6 \mathrm{eV}$ are attributed to $\mathrm{Co}^{3+}$ and $\mathrm{Co}^{2+}$ respectively. The peak with binding energy of $795.6 \mathrm{eV}$, together with the relatively intensive $3 d \rightarrow 4 s$ "shake-up" satellite with binding energy of $803-804 \mathrm{eV}$ are proof for the presence of $\mathrm{Co}^{2+}$ ions in the cobalt-containing samples. Both $\mathrm{Co}^{2+}$ and $\mathrm{Co}^{3+}$ ions are observed in mono-component and bi-component sample having ratio Co:Mn = 1:1 (see Table 1 from Supplementary data). The $\mathrm{Co}^{3+}$ is only cobalt species on the surface of Co:Mn = 1:0.5 sample and all the surface Co ions in the catalyst at ratio 1:2 are in the second oxidation state. The Mn2p peaks are measured in the energy range $635-660 \mathrm{eV}$ consisting of both $\mathrm{Mn} 2 \mathrm{p}_{3 / 2}$ and $\mathrm{Mn} 2 \mathrm{p}_{1 / 2}$ core levels. Both $\mathrm{Mn}^{3+}$ and $\mathrm{Mn}^{4+}$ oxidation states are observed in all measured samples (right-hand side of Fig. 7 from Supplement) with $\mathrm{BE}$ of $640.8 \mathrm{eV}$ and $642.7 \mathrm{eV}$, respectively. The small satellite structure with $\mathrm{BE}$ of about $644.0 \mathrm{eV}$ also proves the presence of $\mathrm{Mn}^{4+}$ ions on the surface, according to the curve fitting procedure [8]. $\mathrm{Mn}^{4+}$ is a predominant species on the surface of all manganese containing samples (see Table 1 Supplement). $\mathrm{Mn}^{3+}$ ions predominate on the surface of single component Mn sample. The increases in the $\mathrm{Mn}$ concentration lead to the increase in the relative abundance of $\mathrm{Co}^{2+}$. The same tendency was observed in our previous investigations regarding bi-component Co-Mn catalysts supported on $\mathrm{SiO}_{2}$ [6] or bulk Co-Mn mixed oxide [19]. Li et al. [20] claim that the doping of $\mathrm{Mn}$ into the structure of $\mathrm{Co}_{3} \mathrm{O}_{4}$ increased crystalline defects, which probably caused the increase in the amount of octahedrally coordinated $\mathrm{Co}^{2+}$.

After reaction of the $n$-hexane oxidation, the results from XPS show the increases in the Co2p1/2/Mn2p ratio for the $1 \mathrm{Co} 0.5 \mathrm{Mn}-\mathrm{MM}$ and 1Co2Mn- MM samples demonstrating enrichment in the Co component. The trend for 1Co1Mn- MM is just the opposite. No clear dependence was found out for changes in the concentrations of $\mathrm{Co}^{2+}, \mathrm{Co}^{3+} \mathrm{Mn}^{3+}$ and $\mathrm{Mn}^{4+}$ speacies after reaction. This is most likely due to the complex 


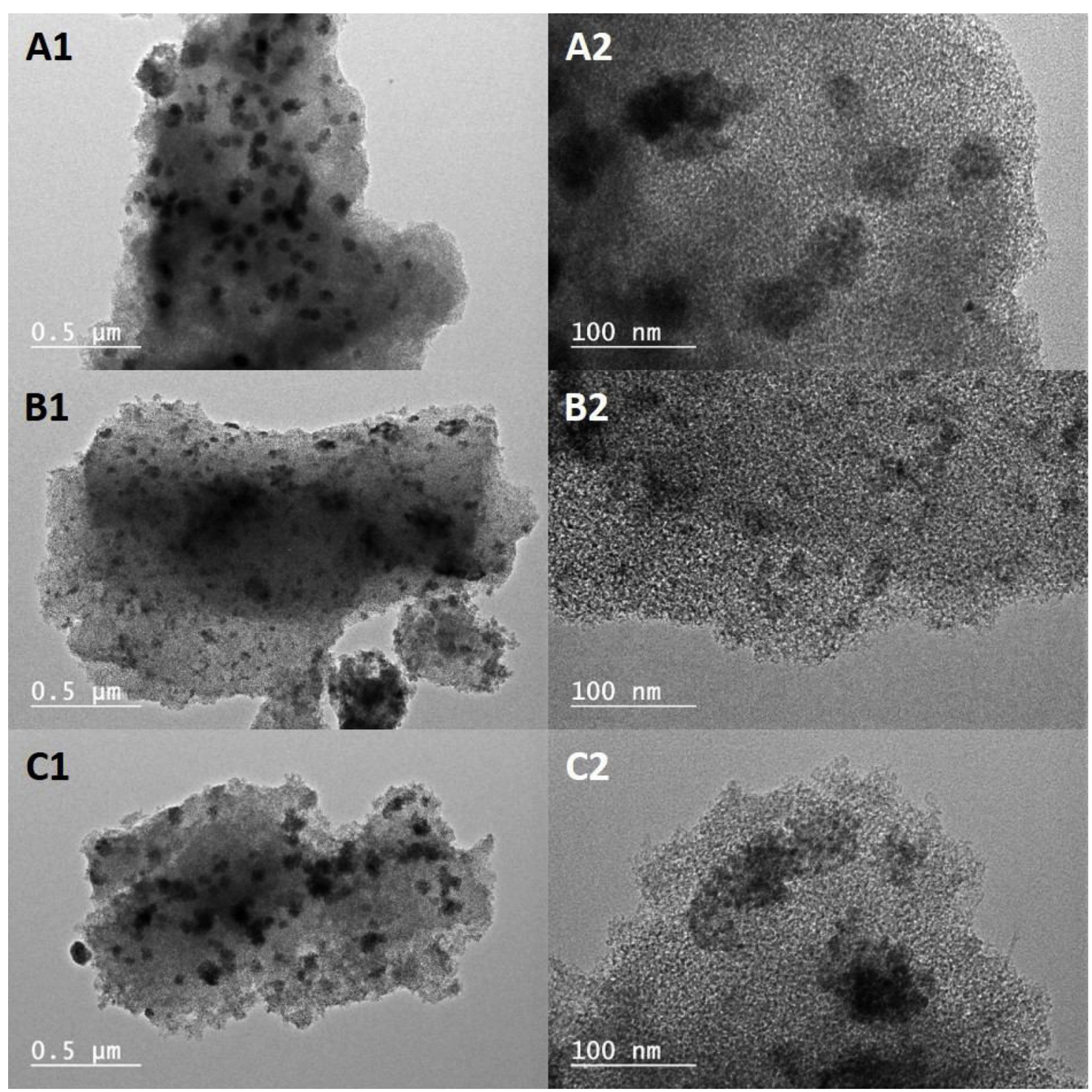

Fig. 5. TEM images of Co (A1, A2), Mn (B1,B2) and mixed oxide CoMn 1:1 (C1, C2) samples before reaction.

composition (as it was shown above the bi-component Co-Mn samples are composed of several oxides) of the system and the ability of the different surface species to participate in the reaction. In our previous investigation [9] we have observed the following trend: increasing the surface concentration of $\mathrm{Mn}^{4+}$ and $\mathrm{Co}^{2+}$ by the same percentage. This was explained by electronic transfer between Co and Mn according the following equation:

$\mathrm{Co}^{3+}-\mathrm{Mn}^{3+} \leftrightarrow \mathrm{Co}^{2+}-\mathrm{Mn}^{4+}$

This trend has not been established for samples supported on macromesoporous silica.

The TPR profiles of all samples are represented in Fig. 6A. It is visible that the mono component cobalt catalyst exibits three reduction peaks. The first two at 327 and $356^{\circ} \mathrm{C}$ are attributed to the reduction of large size supported $\mathrm{Co}_{3} \mathrm{O}_{4}$ particles [9]. The third one, which is centered at $448{ }^{\circ} \mathrm{C}$, is ascribed to small particles strongly interacting with the support [9]. As it was shown by TEM image, a part of $\mathrm{Co}_{3} \mathrm{O}_{4}$ forms a small spherical particle, fitting with the mesopore. The reduction profile of the single component manganese samples corresponds to the two-step reduction of $\mathrm{Mn}_{3} \mathrm{O}_{4} / \mathrm{MnO}_{2} \quad\left(\mathrm{MnO}_{2} \rightarrow \mathrm{Mn}_{2} \mathrm{O}_{3} \rightarrow \mathrm{Mn}_{3} \mathrm{O}_{4}\right.$; $\mathrm{Mn}_{3} \mathrm{O}_{4} \rightarrow \mathrm{MnO}$ ) [21]. Manganese oxide in the monocomponent sample is amorphous as it is visible from XRD data.

Addition of $\mathrm{Mn}$ to the calcined Co sample decreases reduction temperature and this is best visible for the sample with ratio Co:Mn equal of 1:0.5. Two reduction regions are observed in the TPR profile of the bi-component catalysts: the low temperature within the interval $200-400{ }^{\circ} \mathrm{C}$ and high temperature within the range $450-700^{\circ} \mathrm{C}$. Similar reduction behaviour was observed with bi-component catalysts deposited on SBA-15 [9]. By analogy with the previous study, the first two peaks in the low temperature region are attributed to a hydrogen consumption by the easily reducible highly dispersed surface $\mathrm{Mn}^{4+}$ species in nano Co-Mn oxide and adsorbed oxygen species $\left(\mathrm{Co}_{\mathrm{x}} \mathrm{Mn}_{\mathrm{y}} \mathrm{O}_{\mathrm{z}}\right.$ $(\mathrm{s})+\mathrm{H}_{2}(\mathrm{~g}) \rightarrow \mathrm{Mn}_{3} \mathrm{O}_{4}-\mathrm{Co}_{3} \mathrm{O}_{4}(\mathrm{~s})+\mathrm{H}_{2} \mathrm{O}(\mathrm{g})$ ) and the second reduction band is ascribed to the reduction of $\mathrm{Mn}_{3} \mathrm{O}_{4}$ and $\mathrm{Co}_{3} \mathrm{O}_{4}\left(\mathrm{Mn}_{3} \mathrm{O}_{4}-\mathrm{Co}_{3} \mathrm{O}_{4}\right.$ (s) $+\mathrm{H}_{2}(\mathrm{~g}) \rightarrow \mathrm{MnO}-\mathrm{CoO}(\mathrm{s})+\mathrm{H}_{2} \mathrm{O}(\mathrm{g})$ ) $[22,23]$. The third step is ascribed to reduction of $\mathrm{Co}^{2+}$ to metallic phase. As it can be seen, the modification with manganese leads to a shift of the reduction peaks to a lower temperature, indicating that the reduction of the samples increases. By comparing the TPR profiles of the samples deposited on the macro mesoporous silicate with theses supported on SBA-15 [9], it can be seen that the bi-component catalysts deposited on the hierarchical macro mesoporous carrier are reduced at slightly lower temperatures, which shows a better reducibility in the last case.

The information about the type of the oxygen species can be obtained from $\mathrm{O}_{2}$-TPD experiment. The data on the studied catalyst samples are represented in Fig. 6B. Three desorption areas are observed 


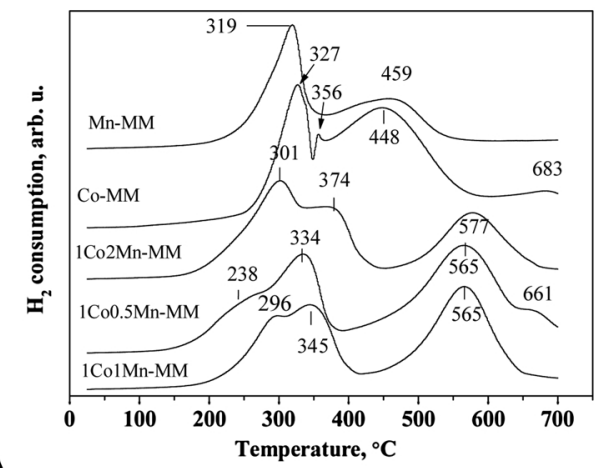

A

Fig. 6. A. TPR spectra of single- and bi-component catalysts and $\mathbf{B}$. $\mathrm{O}_{2}$-TPD profiles of single- and bi-component catalysts.

B in the $\mathrm{O}_{2}$-TPD spectra: $50-250{ }^{\circ} \mathrm{C}, 250-375^{\circ} \mathrm{C}$ and above $375{ }^{\circ} \mathrm{C}$. Taking into account the literature data [24-26] we can ascribe the desorption TPD peak in the first region to the $\mathrm{O}_{2}{ }^{-}$(ad) species in the second interval- to the $\mathrm{O}^{-}$(ad) species and in the region above $375{ }^{\circ} \mathrm{C}$ to the surface lattice oxygen $\mathrm{O}^{2-}$ (ad/lattice). The calculated desorbed amounts of oxygen are: $1.1 \mathrm{mg}$ for Co-MM, $1.0 \mathrm{mg}$. for Mn-MM, 0.8 for 1Co1Mn-MM, 0.7 for $1 \mathrm{Co} 2 \mathrm{Mn}-\mathrm{MM}$ and $1.7 \mathrm{mg}$. for $1 \mathrm{Co} 0.5 \mathrm{Mn}-\mathrm{MM}$. As can be seen the order of desorbed oxygen diminution follows the order of the catalytic activity except for the sample $1 \mathrm{Co} 0.5 \mathrm{Mn}-\mathrm{MM}$ where the desorbed oxygen is the highest.

Here again, as in the case of bi-component catalysts deposited on SBA-15, it is established that the modification of cobalt oxide with manganese moves desorption peaks to the lower temperature and it increases the quantity of desorbed oxygen species. The highest shift to low desorption temperatures is established for the peak associated with the lattice oxygen desorption, which confirms the increased mobility of oxygen species. The increase in the amount of adsorbed oxygen is the result of the increased amount of vacancies, due to low degree of crystallinity of the mixed oxide phases (as it was shown by XRD data) [27].

\subsection{Catalytic activity}

The temperature dependencies of the $\mathrm{CO}$ and $n$-hexane complete oxidation over the mono- and bi-component catalysts are shown in Fig. 5. $\mathrm{H}_{2} \mathrm{O}$ and $\mathrm{CO}_{2}$ were the only detectable reaction products of $n$ hexane oxidation on all investigated samples

As it is evident in Fig. 7, the mono-component cobalt sample is the most active in both studied reactions. In the cases of complete oxidation of $\mathrm{CO}$, this could relate to the predomination of $\mathrm{Co}^{3+}$ species on the surface of $\mathrm{Co}_{3} \mathrm{O}_{4}$ as it is visible from the XPS data. According to the results in literature relating to the oxidation of $\mathrm{CO}$ in the presence of

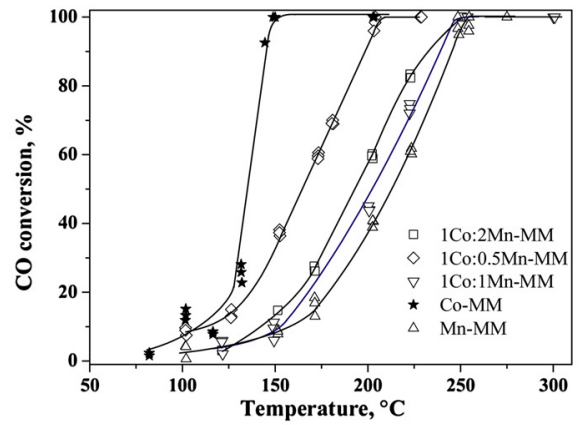

A

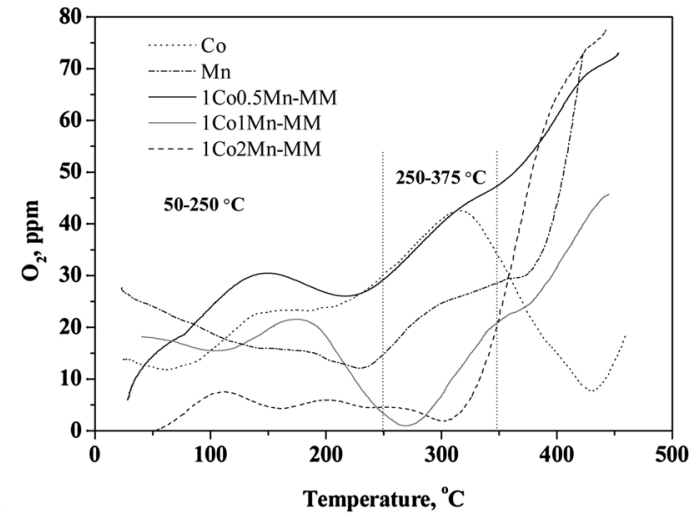

cobalt catalysts, the $\mathrm{Co}^{3+}$ is an active species [28,29]. If we compare the order of activities in $\mathrm{CO}$ oxidation reaction (Fig. 7) and the Table 1 from Supplementary data, it can be seen that the activity is decreasing with decrease in the $\mathrm{Co}^{3+}$ surface concentration. The samples $1 \mathrm{Co} 2 \mathrm{Mn}$ and $1 \mathrm{Co} 1 \mathrm{Mn}$ manifested the relatively similar and lowest activity. $\mathrm{Co}^{2+}$ predominates on the surface of $1 \mathrm{Co} 1 \mathrm{Mn}$ and it is the only species in the case of 1Co2Mn sample.

Fig. 10 from Supplementary data shows comparison at $\mathrm{T}_{50}$ (temperature for $50 \%$ conversion) for catalysts deposited on mesoporous SBA-15 [9] and macro mesoporous silica with the same cobalt /manganese ratios. The catalysts supported on MMS exhibit the higher catalytic activity except for mono-component Co-MM and 1Co1Mn-MM. It was not established the influence of the porosity of the support on the activity of these two samples. A possible explanation could be that in cases of the Co-MM catalyst, the most part of cobalt oxide is located outside the mesopores and it is more readily accessible to the reactants, therefore the presence of a hierarchical system does not affect significantly on the reactants transport to the active sites.

In the reaction of $n$-hexane oxidation, the catalyst displaying highest activity is the mono-component Co-MM sample followed by monocomponent manganese one and the lowest activity is demonstrated by the 1Co2Mn-MM. The 1Co0.5Mn-MM and 1Co1Mn-MM exhibit comparable activity. These results are very different from our previous investigations concerning bi-component Co-Mn catalysts supported on different silica supports as $\mathrm{SiO}_{2}$ [6-8] and SBA-15 [9]. In all these studies it was observed that the bi-component catalysts were more active than the mono-component ones, with the least active being the mono-component manganese sample. In the case of a hierarchical macro-mesoporous silicate support, the higher activity of the Mn-MM catalyst in comparison with that of bi-component could be attributed to the high dispersion degree of manganese oxide and, as a consequence more accessible reaction sites. The possible explanation for the highest

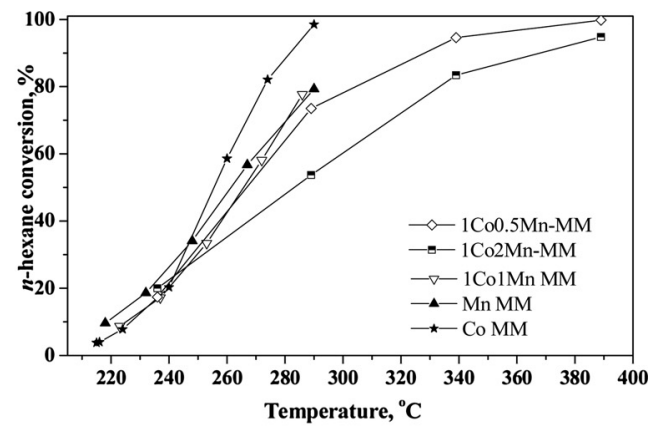

B

Fig. 7. Temperature dependence of A. CO oxidation; B. $n$-hexane combustion. 
catalytic activity of the cobalt sample probably is that the oxide particles are located outside the mesopores and are easily accessible for reagents in this catalyst, whereas in the cases of bi-component catalysts, the oxide particles are encapsulated within the pores of the macromesoporous silica. The similar activity in the complete $n$-hexane oxidation for $1 \mathrm{Co} .5 \mathrm{Mn}-\mathrm{MM}$ and $1 \mathrm{Co} 1 \mathrm{Mn}-\mathrm{MM}$, most likely is due to the similar reductive behaviour of these two samples. In our previous investigation concerning bi-component CoMn samples, supported on $\mathrm{SiO}_{2}$, we established that the $n$-hexane oxidation reaction proceeds through Mars-van Krevelen mechanism [7]. According to this mechanism the substrate is oxidized by the solid. The oxygen species introduced into the substrate come from the lattice. In this way the catalytic behaviour can be correlated to the lattice oxygen mobility of the crystalline framework. As was shown from the O-TPD the lattice oxygen mobility increased after Mn modification.

The comparison of the activity of the catalysts with the same amount of active phase deposited on mesoporous silica SBA-15 [9] and hierarchical macro-mesoporous silica shows that the latter exhibit higher catalytic activity, which could be attributed to the reduction of the transport limitations because of the combination of two levels pores in the case of the hierarchal porous materials (Fig. 11 from Supplement).

\section{Conclusions}

New active cobalt, manganese and bi-component Co-Mn catalysts were prepared by modification of hierarchical macro-mesoporous silica (MMS) by Co and Mn oxides.

The mesoporous structure does not change significantly after deposition of the oxides; however, its pores are partially blocked by the oxide species. The agglomerates with average sizes of 100-150 nm and small spherical aggregates, encapsulated inside mesopores are formed in Co-MM sample. The manganese species present in the form of the amorphous oxide phases preferentially fill up the mesopores. Co and Mn form mixed oxides situated in the mesoporous structure in the CoMn catalysts and form different mixed oxides. No significant change is observed either in the textural or in the structural features of the catalysts after reaction.

The highest catalytic activity for Co-MM sample in $\mathrm{CO}$ and $n$-hexane oxidation is related to the predomination of $\mathrm{Co}^{3+}$ species on the surface of $\mathrm{Co}_{3} \mathrm{O}_{4}$ and the more accessible oxide particles located outside the mesopores. The encapsulation of mixed Co-Mn oxides particles in the pores of the macro-mesoporous silica is responsible for a lower catalytic activity in comparison with that of the mono-component cobalt sample. The higher catalytic activity of the bi-component catalysts supported on MMS comparing with that of samples supported on SBA-15 could be related to the fact the macro-mesoporous network favours the diffusion of the reactants toward the catalytic sites.

\section{CRediT authorship contribution statement}

S. Todorova: Conceptualization, Methodology, Writing - original draft, Writing - review \& editing. J.L. Blin: Conceptualization, Methodology, Writing - original draft, Writing - review \& editing. A. Naydenov: Methodology, Investigation, Writing - original draft, Writing - review \& editing. B. Lebeau: Methodology, Investigation, Writing - original draft, Writing - review \& editing. D. Karashanova: Data curation, Formal analysis, Validation, Writing - review \& editing. H. Kolev: Data curation, Formal analysis, Validation. P. Gaudin: Data curation, Formal analysis. R. Velinova: Data curation, Investigation. L. Vidal: Data curation, Formal analysis, Validation. L. Michelin: Data curation, Validation. L. Josien: . D. Filkova: Data curation, Validation. I. Ivanova: . A. Dotzeva: Data curation. K. Tenchev: Data curation, Validation.

\section{Declaration of Competing Interest}

The authors declare that they have no known competing financial interests or personal relationships that could have appeared to influence the work reported in this paper.

\section{Acknowledgements}

Authors would like to thank DuPont de Nemours Belgium for providing the fluorinated surfactant. Ludovic Josien and Loïc Vidal who are the persons in charge of the X-Ray diffraction and Electronic Microscopy platforms of IS2M, respectively, are warmly thanked.

The Bulgarian authors express their gratitude for the research equipment of distributed research infrastructure INFRAMAT (part of Bulgarian National roadmap for research infrastructures) supported by Bulgarian Ministry of Education and Science under contract D01-155/ 28.08.2018, which was used in this investigation and the European Regional Development Fund within the OP "Science and Education for Smart Growth 2014 - 2020", project №B G05M2OP001-1.001-0008C01.

\section{Appendix A. Supplementary data}

Supplementary material related to this article can be found, in the online version, at doi:https://doi.org/10.1016/j.cattod.2020.01.019.

\section{References}

[1] J.J. Spivey, Catal. Today 100 (2005) 171-180.

[2] A. Kołodziej, J. Łojewska, Catal. Today 105 (2005) 378-384.

[3] A. Cybulski, J.A. Moulijn, Catal. Rev. - Sci. Eng. 36 (1994) 179-270.

[4] S. Roy, T. Bauer, M. Al-Dahhan, P. Lehner, T. Turek, AIChE J. 50 (2004) 2918-2938.

[5] S. Todorova, H. Kolev, J.P. Holgado, G. Kadinov, Ch. Bonev, R. Pereñíguez, A. Caballero, Appl. Catal. B: Environ. 94 (2010) 46-54.

[6] S. Todorova, A. Naydenov, H. Kolev, K. Tenchev, G. Ivanov, G. Kadinov, J. Mater. Sci. 46 (2011) 7152-7159.

[7] S. Todorova, A. Naydenov, H. Kolev, J.P. Holgado, G. Ivanov, G. Kadinov, A. Caballero, Appl. Catal. A: Gen. 414 (2012) 43-51.

[8] S. Todorova, I. Yordanova, A. Naydenov, H. Kolev, Z. Cherkezova-Zhelev, K. Tenchev, B. Kunev, Rev. Roum. Chim. 59 (2014) 259-265.

[9] S. Todorova, J.L. Blin, A. Naydenov, B. Lebeau, H. Kolev, P. Gaudin, A. Dotzeva, R. Velinova, D. Filkova, I. Ivanova, L. Vidal, L. Michelin, L. Josien, K. Tenchev, Catal. Today (2019), https://doi.org/10.1016/j.cattod.2019.05.018.

[10] I. Yordanova, S. Todorova, H. Kolev, Z. Cherkezova-Zheleva, Bulg. Chem. Commun. 49 (Special Issue G) (2017) 99-104.

[11] N. Aligholi, S. Dariush, H. Seyed Ali, J. Azadeh, J. Chin. Chem. 29 (2009) 483-488.

[12] A.Z. Abdullah, M.Z. Abu Bakar, S. Bhatia, J. Chem. Technol. Biotechnol. 79 (2004) $761-768$.

[13] J.L. Blin, B. Bleta, J. Ghanbaja, M.J. Stébé, Microporous Mesoporous Mater. 94 (2006) 74-80.

[14] S. Brunauer, P.H. Emmet, E. Teller, J. Am. Chem. Soc. 60 (1938) 309-319.

[15] E.P. Barrett, L.G. Joyner, P.P. Halenda, J. Am. Soc. 73 (1951) 373-380.

[16] M. Thommes, K. Kaneko, A.V. Neimark, J.P. Olivier, F. Rodriguez-Reinoso, J. Rouquerol, K.S.W. Sing, Pure Appl. Chem. 87 (9-10) (2015) 1051-1069.

[17] S. Zhu, Z. Zhou, D. Zhang, H. Wang, Microporous Mesoporous Mater. 95 (2006) 257-264.

[18] R.M. Rojas, El. Vila, O. Garcia, J.L. Martin de Vidales, J. Mater. Chem. 4 (10) (1994) 1635-1639.

[19] H.G. El-Shobaky, M.A. Shouman, A.A. Attia, Colloid. Surf. A: Physicochem. Eng. Aspects 274 (2006) 62-70.

[20] J. Li, Xi Liang, S. Xu, J. Hao, Appl. Catal. B: Environ. 90 (2009) 307-312.

[21] M. Ferrandon, J. Carnö, S. Järås, E. Björnbom, Appl. Catal. A: Gen. 180 (1999) 141-151.

[22] W. Tang, W. Li, D. Li, G. Liu, X. Wu, Y. Chen, Catal. Lett. 144 (2014) 1900-1910.

[23] J.Y. Luo, M. Ming, L. Xiang, X.G. Li, Y.Q. Zha, T.D. Hu, Y.N. Xie, Z. Jing, J. Catal. 254 (2008) 310-324.

[24] X. Zhang, J. Ye, J. Yuan, T. Cai, B. Xiao, Z. Liu, K. Zhao, L. Yang, D. He, Appl. Catal. A: Gen. 566 (2018) 104-112.

[25] X. Liu, Q. Liu, X.G. Huang, X.L. Nie, Z. Huang, J. Chin. Chem. Soc. 61 (2014) 490-494.

[26] W. Song, Al.S. Poyraz, Y. Meng, Z. Ren, S.-Y. Chen, S.L. Suib, Chem. Mater. 26 (2014) 4629-4639.

[27] M.R. Morales, B.P. Barbero, L.E. Cadús, Fuel 87 (2008) 1177-1186.

[28] L.F. Liotta, X.W. Xie, Y. Li, Z.Q. Liu, M. Haruta, W.J. Shen, Nature 458 (2009) 746-749.

[29] B. Faure, P. Alphonse, Appl. Catal. B: Environ. 180 (2016) 715-772. 